\title{
Probabilistic assessments of climate change impacts on durum wheat in the Mediterranean region
}

\author{
R. Ferrise ${ }^{1}$, M. Moriondo ${ }^{1}$, and M. Bindi ${ }^{2}$ \\ ${ }^{1}$ IBIMET-CNR, Florence, Italy \\ ${ }^{2}$ DiPSA, University of Florence, Florence, Italy
}

Received: 23 December 2009 - Revised: 31 March 2010 - Accepted: 8 April 2011 - Published: 9 May 2011

\begin{abstract}
Recently, the availability of multi-model ensemble prediction methods has permitted a shift from a scenariobased approach to a risk-based approach in assessing the effects of climate change. This provides more useful information to decision-makers who need probability estimates to assess the seriousness of the projected impacts.

In this study, a probabilistic framework for evaluating the risk of durum wheat yield shortfall over the Mediterranean Basin has been exploited. An artificial neural network, trained to emulate the outputs of a process-based crop growth model, has been adopted to create yield response surfaces which are then overlaid with probabilistic projections of future temperature and precipitation changes in order to estimate probabilistic projections of future yields. The risk is calculated as the relative frequency of projected yields below a selected threshold.

In contrast to previous studies, which suggest that the beneficial effects of elevated atmospheric $\mathrm{CO}_{2}$ concentration over the next few decades would outweigh the detrimental effects of the early stages of climatic warming and drying, the results of this study are of greater concern.
\end{abstract}

\section{Introduction}

Durum wheat is a rain-fed crop that is widely cultivated over the Mediterranean Basin. The major climatic constraints to durum wheat yield in Mediterranean environments are high temperatures and drought, frequently occurring during the crop's growth cycle (Porter and Semenov, 2005; García del Moral et al., 2003). As a consequence, projected climate changes in this region, in particular rising temperatures and decreasing rainfall (Gibelin and Déqué, 2003), may se-

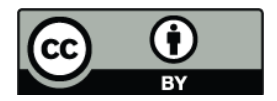

Correspondence to: R. Ferrise (roberto.ferrise@unifi.it) riously compromise durum wheat yields, representing a serious threat to the cultivation of this typical Mediterranean crop.

Crop growth models have been widely used to evaluate crop responses (development, growth and yield) to climate change impact assessments by combining future climate conditions, obtained from General or Regional Circulation Models, with simulations of $\mathrm{CO}_{2}$ physiological effects, derived from crop experiments (see Downing et al., 2000; Ainsworth and Long, 2005). Since future scenarios typically have no associated likelihood, to investigate the uncertainties in future impacts, the effects of climate change are usually estimated over a number of scenarios representing a range of uncertainties as realistic as possible (Mearns et al., 2001).

Recently, the availability of multi-model ensemble prediction methods (e.g. Murphy et al., 2007; Tebaldi and Knutti, 2007) has permitted the assignment of likelihoods to future climate projections. This has allowed a move from the scenario-based approach to a risk-based approach in assessing the effects of climate change (New et al., 2007), providing more useful information to decision-makers, who, as reported by Schneider (2001), need probability estimates to assess the seriousness of the projected impacts.

A probabilistic framework for evaluating crop responses to climate change involves performing a multi-simulation by linking impact models (such as crop growth models) to a very large number of climate projections, so as to provide a probabilistic distribution of the variable selected in order to evaluate the impact (Fronzek et al., 2010). By comparing the outputs of a multi-simulation with a critical threshold (such as the minimum yield below which it is not admissible to fall), it is possible to evaluate the risk related to future climate conditions. Unfortunately, such an approach is timeconsuming, due to the large number of model runs needed for the procedure. An alternative method relies on setting up impact response surfaces (Jones, 2000; Tebaldi and Lobell, 2008) with respect to key climatic variables on which a

Published by Copernicus Publications on behalf of the European Geosciences Union. 
probabilistic representation of projected changes in the same climatic variables may be overlaid.

This approach has been exploited in the ENSEMBLES FP6 EU Project, which aims to assess the climate change impact on typical Mediterranean crops. This study focuses on the assessment of the risk of durum wheat (T. turgidum L. subsp. durum (Desf.) Husn) yield falling below fixed thresholds in the Mediterranean Basin.

\section{Materials and methods}

To perform the probabilistic assessment of climate change impact on durum wheat yield, the procedure adopted involved the following steps:

1. Calibration and validation of a mechanistic durum wheat crop growth model.

2. Simplification of the mechanistic model using an Artificial Neural Network (ANN) to link the model outputs to some key climatic and management variables.

3. Creation of impact Response Surfaces (RSs) for durum wheat over the case study area, altering the baseline climate with respect to key climatic variables (e.g. Temperature (Temp), and Precipitation (Prec), $\mathrm{CO}_{2}$ ).

4. Assessing the risk of yield shortfall using future probabilistic projections for the A1B scenario provided by the Met-Office Hadley Centre.

5. Generation of maps of future risk of durum wheat yield shortfall.

\subsection{Durum wheat impact model calibration and validation}

The Sirius Quality v1.1 model (SIRIUS) was calibrated and validated to simulate winter durum wheat yield. SIRIUS is a wheat simulation model that calculates biomass production from intercepted photosynthetically active radiation and grain growth from simple partitioning rules (Jamieson et al., 1998). The model accounts for the enhanced $\mathrm{CO}_{2}$ effect by linearly increasing radiation use efficiency (RUE), so that for a doubling of $\mathrm{CO}_{2}$ air concentration the RUE is increased by $30 \%$ (Jamieson et al., 2000). A simple soil sub-model is used for the dynamics of water and nitrogen $(\mathrm{N})$ in the ground. As inputs, the model needs daily weather data consisting of minimum temperature ( $T \mathrm{~min})$, maximum temperature ( $T \max )$, Prec and global radiation (Rad). It allows the user to specify management parameters such as the sowing date, cultivar genetic coefficients (e.g. photoperiodic sensitivity, duration of grain filling, minimum and maximum potential leaf numbers, etc.), soil profile properties (e.g. soil hydrological properties, thickness, initial water and nitrogen content, etc.), fertilizer and irrigation management, and atmospheric $\mathrm{CO}_{2}$ concentration.
The SIRIUS model, originally developed for bread wheat, was calibrated to reproduce a general winter durum wheat crop with a medium growing cycle and few vernalization requirements. The calibration was performed using data from two open-field experimental trials carried out in Florence (Italy, $11.11^{\circ} \mathrm{E}, 43.3^{\circ} \mathrm{N}$ ) in 2003-2005 (Triossi, 2006). The thermal time of the main phenological phases (e.g. from sowing to emergence and grain-filling duration), plant day-length response (leaf production per hour of daylight), minimum and maximum leaf numbers, and phyllochrone and vernalisation parameters were the variables calibrated according to experimental evidence.

The accuracy of the calibrated model in reproducing the observed yields was tested on both the local and regional scale to ensure its general applicability. On the local scale, phenological and yield data from 3 sites located in the north (Milano, 9.3 $3^{\circ} \mathrm{E}, 45.4^{\circ} \mathrm{N}$ ), middle (Roma, $12.2^{\circ} \mathrm{E}, 41.8^{\circ} \mathrm{N}$ ) and south (Foggia, $15.7^{\circ} \mathrm{E}, 41.5^{\circ} \mathrm{N}$ ) of the Italian peninsula were used as an independent data set. Yield and phenological data, soil properties and crop management data (e.g. sowing date, amount and splitting of $\mathrm{N}$ fertilisation) were provided by the Istituto Sperimentale per la Cerealicoltura for the periods 1999-2003 for Milano and Roma and 2000-2004 for Foggia. For each site, daily values of $T$ min, $T \max$, Prec and Rad were obtained by the Italian Meteorological Service.

In order to analyse the performance of SIRIUS in simulating yield on the regional scale, the model was run for a selected number of places evenly distributed across the Mediterranean Basin. The outputs of the model were compared with the observed yield data for durum wheat, obtained by the Statistical Office of the European Commission. This dataset has a different time series according to the country and the crop considered: in general, longer time series were available from 1989 to 2004, but in some cases they were limited to $6 \mathrm{yr}$.

A complete series of observed $50 \mathrm{~km}$ daily interpolated meteorological data ( $T$ min, $T$ max, Prec and Rad), extracted from Monitoring Agricultural ResourceS (MARS) of the Joint Research Centre (JRC) archive (MARS, 2009), was processed and adapted to the requirements of the weather files managed by the SIRIUS model.

Since crop management practices are not retrievable on such a spatial scale, a climatic criterion was adopted to identify the optimum sowing date: sowing was matched with the point when the mean temperature fell below $13^{\circ} \mathrm{C}$ for 5 consecutive days and rainfall was $<2 \mathrm{~mm}$ in the period between 1 October and 15 February. Nitrogen fertilization was set at $100 \mathrm{~kg} \mathrm{~N} \mathrm{ha}^{-1}$, split in two applications: $1 / 3$ during tillering (beginning of March) and 2/3 at shooting (mid April). 


\subsection{Emulating the SIRIUS model outputs}

To reduce the computing time needed to apply the procedure over such a wide area as the Mediterranean Basin and for several time slices, an ANN was adopted to simplify the SIRIUS model.

The ANN is a computer system based on several simple and highly interconnected processing elements similar to the neural architecture of the human brain (McClelland and Rumelhart, 1986) and it was adopted to exploit the non-linear relationship between predictor variables (climate, soil, management) and SIRIUS outputs. The ANN approach is being used in several disciplines (Widrow et al., 1994) because of its ability to perform non-linear modelling without a priori knowledge about the relationships between input and output variables (Bindi and Maselli, 2001; Zhang et al., 1998).

The ANN structure adopted was a multilayer perceptron (MLP) with a feed-forward configuration. This structure, selected because of its capacity to solve climate problems, has been well demonstrated in several previous studies (Gardner and Dorling, 1998; Trigo and Palutikof, 1999). More specifically, in this study, an ANN-MLP structure with three layers and 20 hidden nodes was selected. A non-linear transfer function (log-sigmoid) was selected for all nodes and layers, and a back-propagation algorithm (Rumelhart et al., 1986) was used for training the ANN. The optimal number of hidden nodes (over a range of 5-25 with a 5-node step) and the correct learning rate and momentum were determined by carrying out a sensitivity analysis (Moriondo and Bindi, 2006).

The ANN was trained using the outputs from SIRIUS obtained for a wide range of climate, soil and management practices in order to reproduce yield variability over the Mediterranean domain. Daily climatic data for Temp, Prec and Rad for a 30-year period (1975-2005) were extracted from the MARS-JRC archive. Nine grid cells, representative of the climatic variability of the Mediterranean Basin, with particular attention to the winter and spring regime of Temp and Prec, were first selected. For this purpose, all grid points in the study area were grouped with respect to annual, winter and spring total Prec and mean Temp, using K-means cluster analysis. Within each group, one grid point was randomly selected to perform a scenario sensitivity analysis by changing daily Temp and Prec from $-2{ }^{\circ} \mathrm{C}$ to $+10^{\circ} \mathrm{C}\left(2{ }^{\circ} \mathrm{C}\right.$ step) and from $-60 \%$ to $+40 \%$ ( $20 \%$ step), respectively. The selected grid cells and the central values of Temp and Prec of the corresponding class resulting from the cluster analysis are summarized in Table 1.

For each combination of Temp and Prec changes, the SIRIUS model was run for 5 different $\mathrm{CO}_{2}$ concentration levels (from $350 \mathrm{ppm}$ to $750 \mathrm{ppm}$, with $100 \mathrm{ppm}$ step), 3 different soil types (Table 2$)$ and $3 \mathrm{~N}$ fertilization rates $(110,170$ and $\left.230 \mathrm{~kg} \mathrm{~N} \mathrm{ha}^{-1}\right)$. For each of the 17010 resulting combinations ( 7 Temp $\times 6$ Prec $\times 5 \mathrm{CO}_{2} \times 3$ soils $\times 3 \mathrm{~N}$ fertilization rates $\times 9$ grid cells), the average grain yield over the 30 - year period was calculated from the output of the SIRIUS model and used as predictand variables for training the ANN.

The predictor variables for the ANN training were selected considering the approach proposed by Olesen et al. (2007). Five input variables were selected to take into account the effects of soil, crop management and climate conditions and used as predictors to train the ANN over the 9 grid points:

- Soil water content (SWC), calculated as the difference between field capacity and wilting point, in $\mathrm{mm}$

- Nitrogen fertilization rate, in $\mathrm{kg} \mathrm{N}^{-1}$

- $\mathrm{CO}_{2}$ concentration, in ppm

- T (AMJ): mean spring temperature (April, May, June)

- P (AMJ): cumulated spring rainfall.

At the onset, data for all seasons were considered as predictors, but those related to spring had the best predicting performances. Dropping the variables relevant to winter, summer and autumn did not affect the predictive accuracy of the ANN and at the same time increased ANN computation efficiency during the training phase.

As with any other statistical model, ANNs should generally be trained (calibration) and tested (validation) using 2 independent data sets. In this paper, two different strategies were used to derive the subsets for calibration and validation, namely simple validation and cross validation. In the first case, the ANN was trained using a random selection from the initial dataset (80\%) while the remaining $20 \%$ was used as independent data to test its efficiency. The second validation strategy consisted of a Leave-One-Out cross-validation test in which one site in turn was omitted from the training subset and used to test the ANN efficiency. In order to avoid over-fitting problems, both strategies included internal testing during the calibration phase, which was performed on $20 \%$ of the training subset used as independent data.

The accuracy of the SIRIUS and the ANN model in simulating durum wheat yield was calculated using: (1) root mean square error (RMSE); (2) mean absolute error (MAE) and (3) Pearson's correlation coefficient.

\subsection{Case study area and impact response surfaces}

The domain included in the window $34.2^{\circ}-46.0^{\circ}$ Lat $\mathrm{N}$ and $-9.5^{\circ}-28.2^{\circ}$ Lon $\mathrm{E}$ was selected as the case study area to perform the probabilistic assessment of climate change impacts on winter durum wheat yield over the Mediterranean Basin.

The baseline climate for this area was obtained from the ENSEMBLES E-OBS dataset (Haylock et al., 2008), which consists of $25 \mathrm{~km}$ interpolated daily observed data for Prec, $T$ min and $T$ max covering the period 1950-2006. Grid cells relevant to areas of altitude over $700 \mathrm{~m}$ a.s.l., where durum 
Table 1. Location of the nine grid points selected to perform the SIRIUS sensitivity analysis for producing the ANN training set and central values of annual, winter and spring temperatures $\left({ }^{\circ} \mathrm{C}\right)$ and precipitation $(\mathrm{mm})$ of the corresponding climate class.

\begin{tabular}{|c|c|c|c|c|c|c|c|c|c|}
\hline \multirow[t]{2}{*}{ Region } & \multirow[t]{2}{*}{ Latitude } & \multirow[t]{2}{*}{ Longitude } & \multirow[t]{2}{*}{ Altitude } & \multicolumn{3}{|c|}{ Temperature } & \multicolumn{3}{|c|}{ Precipitation } \\
\hline & & & & Annual & Winter & Spring & Annual & Winter & Spring \\
\hline Southern Italy (Sicily) & 37.24 & 14.91 & 271 & 17.1 & 10.4 & 18.6 & 429 & 163 & 50 \\
\hline Turkey (Aydin) & 37.51 & 27.54 & 273 & 17.1 & 10.7 & 18.5 & 625 & 231 & 85 \\
\hline Central Greece (Thessalia) & 39.29 & 22.11 & 304 & 15.7 & 9.1 & 17.5 & 521 & 144 & 104 \\
\hline North-eastern Spain (Aragon) & 41.12 & 0.34 & 312 & 16.1 & 9.9 & 17.7 & 360 & 92 & 88 \\
\hline Central Italy (Lazio) & 41.87 & 12.31 & 60 & 15.9 & 9.6 & 17.3 & 827 & 252 & 133 \\
\hline North-western Spain (Galicia) & 43.27 & -8.13 & 316 & 14.2 & 9.8 & 15.0 & 1592 & 453 & 322 \\
\hline Central France (Midi-Pyrenees) & 44.43 & 2.38 & 517 & 13.4 & 7.8 & 15.0 & 1047 & 263 & 239 \\
\hline North-western Italy (Piedmont) & 44.62 & 8.05 & 349 & 12.7 & 5.8 & 15.4 & 869 & 172 & 227 \\
\hline North-eastern Italy (Veneto) & 45.05 & 11.23 & 10 & 13.9 & 7.4 & 15.9 & 690 & 155 & 163 \\
\hline
\end{tabular}

Table 2. Characteristics of soils used to train the ANN. Soil Water Content $(\mathrm{mm})$ calculated as difference between water content at field capacity and at wilting point for $1 \mathrm{~m}$ depth.

\begin{tabular}{llll}
\hline & \multicolumn{3}{c}{ Soil class } \\
& Sandy & Loamy & Silty \\
\hline Sand \% & 92 & 37 & 7 \\
Clay \% & 5 & 20 & 8 \\
Field Capacity (vol\%) & 13 & 27 & 31 \\
Wilting Point (vol\%) & 6 & 12 & 10 \\
Soil Water Content (SWC) & 70 & 140 & 210 \\
\hline
\end{tabular}

wheat is not usually cultivated, were excluded from the following analyses, as well as a few zones of the Italian Peninsula (e.g. Sardinia, Sicily and Calabria) and Southern Greece, for which there is a lack of weather data on the present and future climate.

Next, the baseline climate was then calculated on a gridcell basis as the monthly average of $T$ min, $T$ max and cumulated Prec over the period 1961-1990. For each grid cell of the domain, the trained ANN was used to create the durum wheat yield RSs for future periods (see below). The RSs were created for the different time slices using the baseline climate perturbed over a range of $-2^{\circ} \mathrm{C}$ to $+10^{\circ} \mathrm{C}$ for annual Temp and $-60 \%$ to $+40 \%$ for annual Prec, and assuming no seasonal variations in the future climate pattern. For each future time slice, the $\mathrm{CO}_{2}$ air concentration level was set according to the A1B SRES emission scenario (Nakićenović and Swart, 2000). SWC and N fertilization were considered as constant for all the grid points and set at $125 \mathrm{~mm}$ and $170 \mathrm{~kg} \mathrm{Nha}^{-1}$, respectively.

\subsection{Future climate probabilistic projections and climatic risk}

Probabilistic projections of future climate changes were provided by the Met-Office Hadley Centre (MOHC) as joint probability distribution functions (PDFs) for annual surface temperature change and annual percentage precipitation change for the A1B scenario with respect to the 1961-1990 baseline period. The PDFs provide a measure of the uncertainty of the future climate and represent changes in the 20year average climate for decadal steps for the periods 20102030 to $2080-2100$, calculated for the $2.5^{\circ}$ latitude by $3.75^{\circ}$ longitude HadCM3 grid boxes covering the whole of Europe (Harris et al., 2010).

In this study, the PDFs were employed as 10000 random, equally-likely projections of the same variables sampled from the PDFs. The use of 10000 points is a good compromise to represent the PDF, but may not give a particularly smooth picture of it.

The PDFs of each grid cell were overlaid on the relevant RSs calculated for each $25 \mathrm{~km}$-spaced grid cell of the ENSEMBLES E-OBS dataset to produce the corresponding probabilistic distributions of future yields.

To estimate the climatic risk of durum wheat shortfall in the next century, the future yield projections were compared with a critical threshold, calculated as the 30-year mean yield for the reference period (1961-1990). The climatic risk of durum wheat yield shortfall was then defined as the relative frequency of future yield projections below the threshold, representing the likelihood of future yields being lower than the present-day long-term mean yield. 
Table 3. Results of SIRIUS validation at regional scale. The Pearson's coefficient was 0.88 and RMSE $0.46 \mathrm{Mg} \mathrm{ha}^{-1}$.

\begin{tabular}{lllll}
\hline Regions & Latitude & Longitude & $\begin{array}{l}\text { Observed yield } \\
\left(\mathrm{Mg} \mathrm{ha}^{-1}\right)\end{array}$ & $\begin{array}{l}\text { Simulated yield } \\
\left(\mathrm{Mg} \mathrm{ha}^{-1}\right)\end{array}$ \\
\hline Southern France & 43.65 & 4.96 & 3.26 & 3.62 \\
Northern Italy & 45.48 & 11.88 & 4.88 & 4.53 \\
Central Italy & 42.34 & 11.73 & 2.94 & 3.58 \\
Southern Italy & 37.78 & 12.68 & 2.17 & 2.21 \\
Central Greece & 39.73 & 22.19 & 3.02 & 2.83 \\
Southern Spain & 36.83 & -5.34 & 2.57 & 3.32 \\
\hline
\end{tabular}

\section{Results}

\subsection{Calibration and validation of SIRIUS and ANN models}

On the local scale, SIRIUS was able to adequately simulate both the phenology and yield of durum wheat in all three locations. In particular, Pearson's correlation coefficient between the observed and simulated values turned out to be very high for both anthesis date $(r=0.87)$ and yield $(r=0.87)$, whilst the overall RMSE of simulations was 3.3 days and $0.371 \mathrm{Mgha}^{-1}$ for anthesis and yield respectively.

On the regional scale, the ability of the model to reproduce yields was poorer. When considering all the validation sites and years, the Pearson's correlation coefficient and RMSE were 0.66 and $0.97 \mathrm{Mg} \mathrm{ha}^{-1}$ respectively. The greater uncertainty of the model on the regional scale may be ascribed to the large geographical area and the limitations of the observed data in fully characterizing spatial variability. For instance, observed yields are largely influenced by management strategies and soil conditions, which vary by farm and region, and which are difficult to measure and include in process-based crop models on this scale (Reidsma et al., 2009).

Importantly, the comparison between the observed and simulated average yields (Table 3 ) indicates that the model captured the spatial variability of yield very well $(0.88$ and $0.46 \mathrm{Mg} \mathrm{ha}^{-1}$, Pearson's coefficient and RMSE, respectively) and was thus held to be trustworthy in reproducing the spatial difference in crop yield for present and future climate conditions.

The test analyses showed a high level of correspondence between the SIRIUS outputs and the ANN simulated yields, indicating the robustness of the proposed approach in emulating the results of the mechanistic model. In particular, the Pearson's coefficients for the simple and cross validations were over 0.94, whereas the RMSE and MAE were just below $0.47 \mathrm{Mg} \mathrm{ha}^{-1}$ and $0.37 \mathrm{Mg} \mathrm{ha}^{-1}$, respectively.

In any case, the RMSEs calculated for grain yield by both the SIRIUS and ANN models were comparable to those
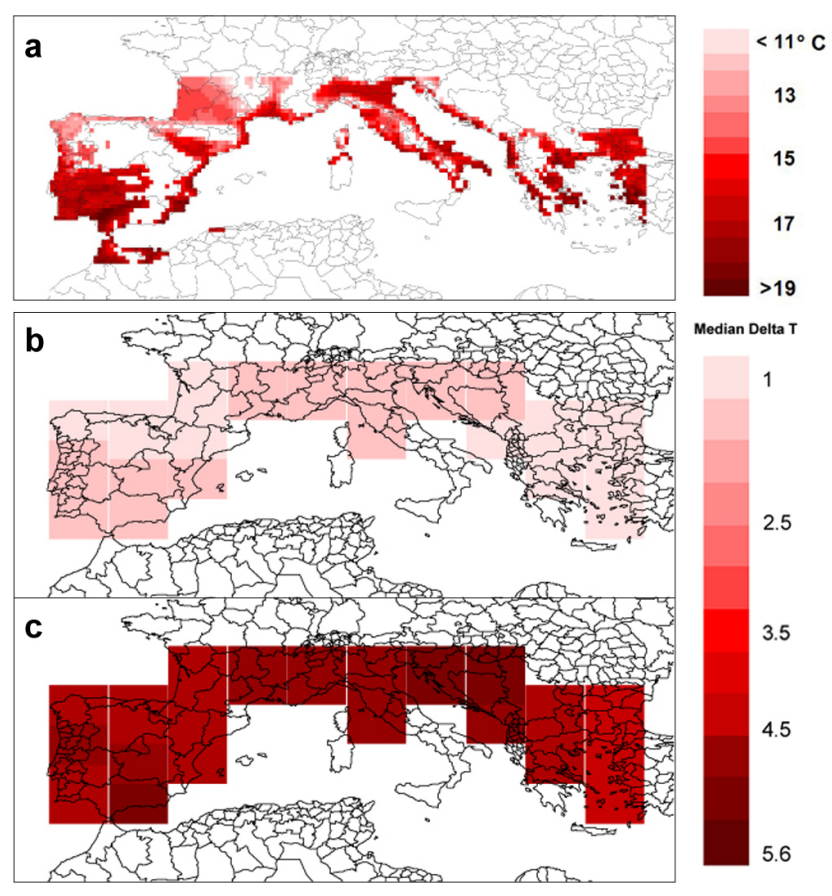

Fig. 1. Spatial distribution of present-day (1961-1990) mean temperature over the period April, May, June (a), and 50th percentile of the probability distribution of temperature change projected for 2010-2030 (b) and 2070-2090 (c).

reported for the main wheat models for bread wheat (David and Jeuffroy, 2009)

\subsection{Baseline and future climate over the study area}

The picture for the baseline period indicates that mean $\mathrm{T}(\mathrm{AMJ})$ over the study area ranged from $10.9^{\circ}$ to $19.6^{\circ}$ (Fig. 1a). The warmest regions were the south of the Iberian Peninsula and the eastern regions, while the coldest regions were located in Galicia and south-western France. The future climate change was represented as the 50th percentile of the probability distribution, while the uncertainty in projections was expressed as the difference between the 10th and 90th percentiles of the distribution. On average, 

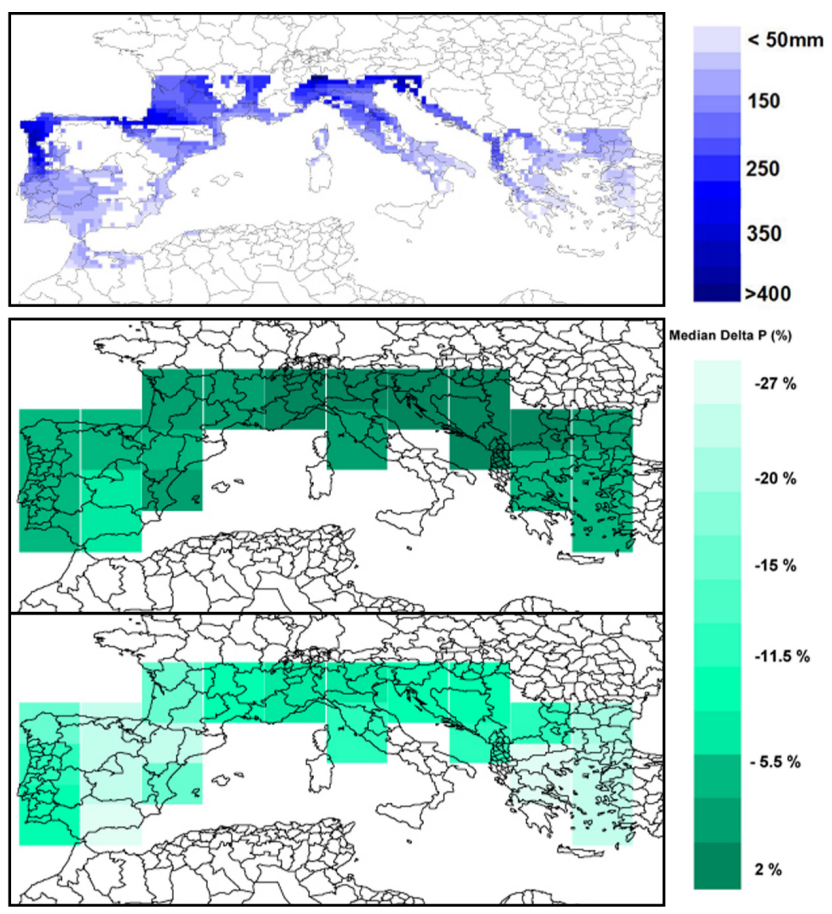

Fig. 2. Spatial distribution of present-day (1961-1990) cumulated precipitation over the period April, May, June (a), and 50th percentile of the probability distribution of percentage precipitation change projected for 2010-2030 (b) and 2070-2090 (c).

median temperature changes vary from $1.6^{\circ} \mathrm{C}$ in $2010-2030$ (Fig. 1b) to about $5^{\circ} \mathrm{C}$ at the end of the century (Fig. 1c). The greatest increases within the study area were predicted for the southern areas of central Europe, while the smallest increases were projected for the eastern regions of the domain and Galicia and Western France. The range of uncertainty varied substantially with the time-distance of future periods and rose to $4.4^{\circ} \mathrm{C}$, on average, by the end of the century.

The mean $\mathrm{P}(\mathrm{AMJ})$ showed a clear latitudinal pattern, with lower values at lower latitudes (Fig. 2a). The greatest precipitation were recorded in Galicia, the Pyrenees and the Northern Balkans region, with more than $300 \mathrm{~mm}$, whereas southern Italy and the south-eastern areas showed the driest climate with less than $100 \mathrm{~mm}$ of rainfall. As regards the future climate, a progressive decrease in precipitation was projected over the whole study area (Fig. 2b, c). Over the next decades, the decrease will be moderate and in some northeastern regions a slight increase is expected, but at the end of the century the reduction will be widespread and more severe in the central Iberian Peninsula and Greece (more than 20\% reduction). Also for precipitation, the range of uncertainty will increase as the century progresses and for many grid boxes there are significant probabilities of both drier and wetter climates.

\subsection{Simulated durum wheat yield under present-day climate conditions}

The simulated durum wheat yield for the baseline period ranges from 2.9 to $7.2 \mathrm{Mg} \mathrm{ha}^{-1}$ with a clear latitudinal gradient. The highest yields are estimated in Southern France and Galicia, with more than $6.5 \mathrm{Mg} \mathrm{ha}^{-1}$ (Fig. 3). Higher yields were also simulated in north-eastern areas of the case study area with a layer in north-western and central Italy, while smaller yields, down to $3.5 \mathrm{Mg} \mathrm{ha}^{-1}$, were estimated for southern areas of the Mediterranean Basin. These results are in agreement with other European-scale assessments of the productivity of wheat (Harrison et al., 1995), once more confirming the robustness of the ANN procedure in simplifying SIRIUS, allowing adequate reproduction of the spatial variability of yield over a wide area, but with much computing time saving.

\subsection{Risk over the study area}

In contrast to previous studies which suggest that the beneficial effects of elevated atmospheric $\mathrm{CO}_{2}$ concentration over the next few decades would outweigh the detrimental effects of the early stages of climatic warming and drying (e.g. Olesen and Bindi, 2002; Parry et al., 2004), the results of our analysis bring more concern (Fig. 4a). Early in the next decades, the risk of reductions in yield below the long term yield average is quite high and widespread. As the century progresses, for a large part of the study area the risk still increases, reaching its maximum by mid century (2050-2070, Fig. 4b,c). In the last period (2070-2090, Fig. 4d), the risk slightly decreases with respect to the previous time slice with the effect of larger uncertainty in climate projections simulated for the end of the century. In some regions, for instance, southern Portugal (grid cell centroid -7.5 lon E, 37.5 lat N) Prec in 2050-2070 is expected changing in the range of $+9 \%$ to $-42 \%$ (10th and 90th percentile respectively; data not shown). In the same area, at the end of the century Prec may range +28 to $-43 \%$, which slightly decreases the risk, given the effect of the positive impact of higher precipitations on yield.

Only a few areas in the northern fringes of the Mediterranean domain (i.e. Galicia, the western side of the Pyrenees and Slovenia) show a low risk of yield falling below the baseline long-term mean yield. For these areas, precipitation does not represent a limiting factor, even considering the decreasing trend for future periods. For instance, in Galicia, presentday $\mathrm{P}(\mathrm{AMJ})$ is about $300 \mathrm{~mm}$ and the highest median precipitation change was $-18 \%$ in $2070-2090$. The projected precipitation does not limit crop growth, because the shortening of the growing season as the effect of the increasing temperature is compensated for by increased radiation and water use efficiency explained by rising $\mathrm{CO}_{2}$ air concentration. 


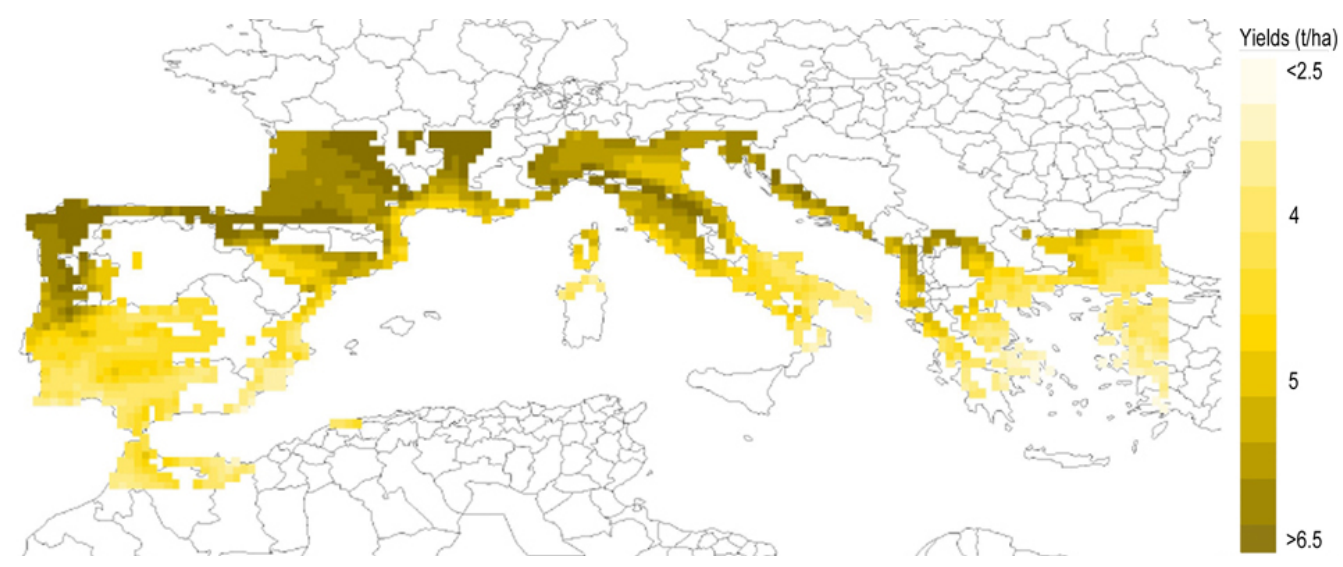

Fig. 3. Spatial distribution of the simulated 30-year mean durum wheat yield for the reference period (1961-1990) over the case study area.

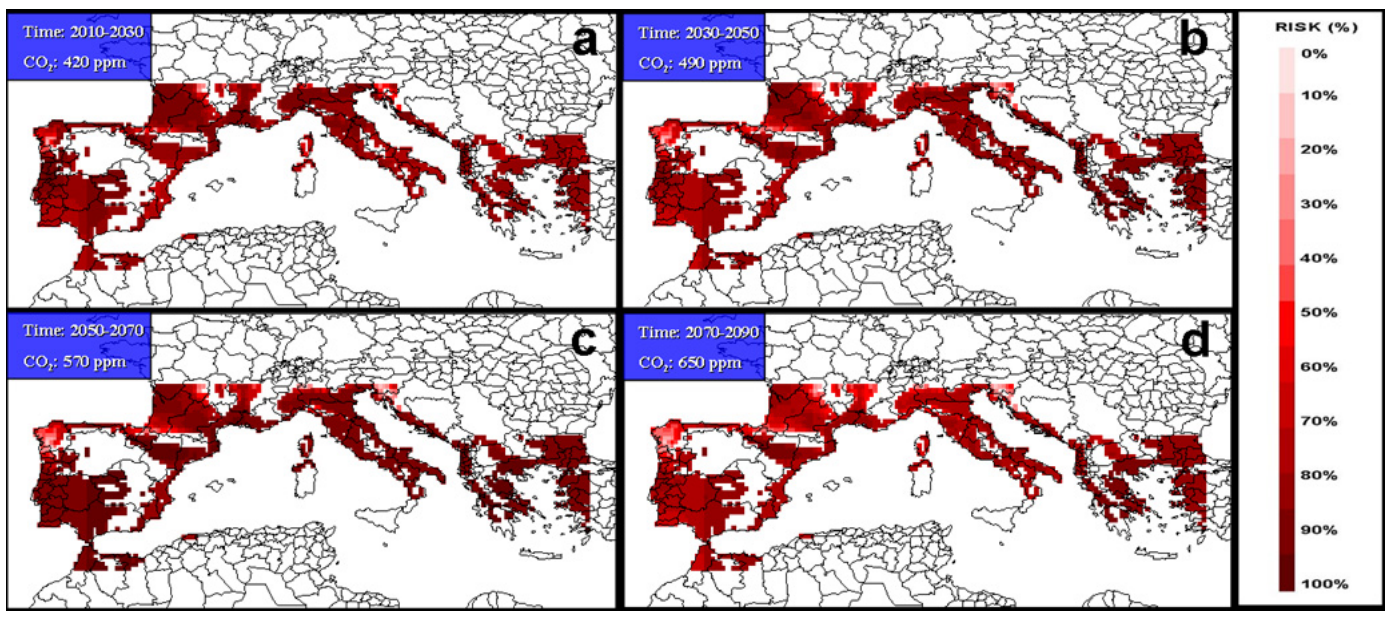

Fig. 4. Spatial plots of risk of durum wheat yield shortfall by: (a) 2010-2030, (b) 2030-2050, (c) 2050-2070 and (d) 2070-2090. The risk was calculated as the relative frequency of future projected yields that do not overcome the selected threshold (30-year mean yield estimated from the baseline).

\section{Discussion}

The probabilistic projections provided by the $\mathrm{MOHC}$ are in accordance with other ensembles analyses based on the most advanced sets of global and regional climate model simulations, giving a collective picture of substantial drying and warming of the Mediterranean region (Giorgi and Lionello, 2008). This trend is expected to greatly affect the performance of rain-fed crops, such as durum wheat. Higher temperatures, which increase the crop development rate, shorten the crop growing cycle, thus reducing the time for biomass accumulation. A decreasing rainfall rate may result in increasing crop water stress. On the other hand, enhanced $\mathrm{CO}_{2}$ concentration, increasing the efficiency in the use of both water and radiation, is expected to reduce the impact of climatic change on yield arising from a warmer and drier climate (Giannakopoulos et al., 2009; Olesen and Bindi, 2002; Kimball et al., 2002).
These phenological and physiological responses have been implicitly taken into account during the training of the ANN, which was based on the SIRIUS simulations as driven by all the possible combinations of Temp and Prec changes encompassing the prospected changes in climate (changes from $-2{ }^{\circ} \mathrm{C}$ to $+10{ }^{\circ} \mathrm{C}$ and from $-60 \%$ to $+40 \%$ in Temp and Prec, respectively).

The response of a crop to climate depends not only on the mean climate but also on the seasonal distribution of the climatic variables. In our study this was taken into account by training the ANN with the outputs of a sensitivity analysis of the SIRIUS model conducted over grid cells with different seasonal distributions of Temp and Prec, representing the observed climate variability of the domain. The ANN was able to reproduce the SIRIUS outputs over all the domain simply by using mean spring temperature and precipitation in accordance with studies affirming that wheat yield is highly sensitive to the climate conditions occurring during the second 
part of the growing season (see García del Moral et al., 2003). Nevertheless, using mean annual changes of Temp and Prec, we have assumed no seasonal variations in the pattern of the future climate, therefore the results may not necessarily hold true if the future seasonal distributions of the climatic variables are greatly different from those employed in training the ANN.

The response surfaces approach avoids the very large number of model runs needed to estimate the impact likelihoods directly from the probabilistic climate projections. In fact, to create the impact response surfaces, the model runs were restricted to a number that was sufficient to cover the likely range of prospected future changes. Once the response surfaces had been constructed, the PDFs describing future changes in the appropriate variables could be superimposed to provide PDFs of the impact to compare with the threshold selected to define the risk related to climate change.

Nevertheless, the methodology may present some limitations. The major disadvantage of the RSs approach is that it may not be appropriate when impact models are critically dependent on several variables, requiring the construction of RSs in multi-dimensional space. In this case, the number of model runs necessary to cover all the possible combinations of the variables selected increases exponentially and the interpretation of the resulting RSs may be greatly complicated. On the other hand, constructing two-dimensional impact RSs necessarily requires a simplification of the model or an assumption about the relationship of the two selected variables with respect to all the variables explaining the phenomenon analysed.

In this paper our analysis has focused on the risk of yield shortfall related to climate change and other sources of uncertainty have not been evaluated. In particular those related to (1) the impact model, (2) the statistical model to simplify the impact model and (3) the future values of the explanatory variables other than Temp and Prec require further consideration.

Crop growth models, although mechanistic, may contain many simple empirically-derived relationships that do not completely represent actual plant processes. Several aspects, such as weeds, pests, extreme climate events and soil conditions (i.e. salinity or acidity) are not considered or scarcely controlled for, representing another source of uncertainty.

Uncertainty increases when statistical models are used to simplify the process-based impact model. As reported by Iglesias et al. (2009), using statistical models to represent process-based crop responses accounting for the most important environmental and management variables allows an easy expansion of the analysis over large areas, but only partially explains causal mechanisms, and introduces another source of uncertainty due to simplifications or assumptions of how the explanatory variables can be related to the full set of required input variables.
Exploring such uncertainties, considering the adoption of several impact models as well as different statistical models in the assessment of risk, would be an interesting topic for future work.

The risk observed in a business-as-usual scenario (i.e. using common crop management, medium growing cycle cultivars, medium SWC, no irrigation) may be reduced by using adaptation strategies to contrast the negative effects of a warmer and drier climate. Changes in crop characteristics or crop management aiming to decrease crop exposure to water and heat stress and lengthen the crop growing cycle, should be considered (Iglesias et al., 2009).

Accordingly, strategies for adapting to climate change should concentrate on the use of drought-tolerant cultivars, increasing water-use efficiency, and better matching phenology to new environmental conditions. The shortening of the growth cycle is a noticeable yield-reducing factor and the selection or use of cultivars with a longer cycle may be suggested as a way of compensating for the reduced time they have for biomass accumulation under warmer conditions (Tubiello et al., 2000). In the Mediterranean region, cultivars with an earlier anthesis may be selected, as this will allow the grain-filling period to occur in cooler and wetter periods, avoiding summer drought and heat stress. Management practices promoting advanced phenological stages, such as earlier sowing, may be adopted as well (Moriondo et al., 2010). Enhanced drought tolerance should be the characteristic most desired in a typical rain-fed crop of the Mediterranean basin, but other strategies should be considered, such as the application of irrigation in the crop-growth stages that are more sensitive to water stress (Zhang and Oweis, 1999), or deep ploughing to increase the available water content of the soil.

Finally, a crucial step in the risk-based inverse approach consists of the selection of the appropriate threshold, and the results could be different depending on its definition. In this paper, we have selected the long-term average yield as a threshold defining the risk of low production. This is a general threshold based on the equilibrium climate-yield where yields below that limit do not imply a risk of hunger nor an economic risk, since no information is given about the production level of each site. For instance, a slight increase in risk in areas with a low production level may be more detrimental economically with respect to a higher risk in areas with a higher production level. In the first case, the crop revenue may be so low that even a minor negative deviation from the median yield results in a negative impact to the farmer's income. On the other hand, in the second case the median yield is so high that even major negative deviations from it do not put the farmer's revenue at risk. Accordingly, specific thresholds should be adopted depending on specific exigencies, which may be based on economic or other issues. 


\section{Conclusions}

In this work we have presented a novel approach to climate change impact assessment in agriculture. This approach has permitted us to evaluate climate change impacts in terms of risk over the wide area of the Mediterranean Basin, with great computing-time saving. The methodology, although introducing additional uncertainty, has allowed us to assess the risk of crop shortfall related to climate change by assigning probability estimates of the impact instead of providing only uncertainty ranges of the possible impact, with no information on relative likelihoods.

The results of this analysis, in contrast to previous studies, indicate that the projected warmer and drier climate over the Mediterranean basin will increase the risk of yield loss, while the positive effects of increasing $\mathrm{CO}_{2}$ are not able to completely counterbalance this trend. In a few areas, at the northern latitudes of the domain, the risk is lower, as the result of the combined effect of non limiting precipitation and increased $\mathrm{CO}_{2}$. Uncertainties in future climate projections progressively increase up to the end of the century, resulting in a reduction of risk.

For a more comprehensive analysis of the risk, further works are needed to take into account the other sources of uncertainty and investigate the possible adaptation strategies needed to cope with future climate change.

Acknowledgements. The authors thank their colleagues for their continuing support and discussion in coffee breaks. Special thanks go to Giacomo "Jack" Trombi and Camilla Dibari for their help in producing figures and their GIS support, respectively.

Edited by: J. E. Olesen

Reviewed by: three anonymous referees

\section{References}

Ainsworth, E. A. and Long, S. P.: What have we learned from 15 years of free-air $\mathrm{CO}_{2}$ enrichment (FACE)? A meta-analytic review of responses to rising $\mathrm{CO}_{2}$ in photosynthesis, canopy properties and plant production, New Phytol., 165, 351-372, 2005.

Bindi, M. and Maselli, F.: Extension of crop model outputs over the land surface by the application of statistical and neural network techniques to topographical and satellite data, Clim. Res., 16, 237-246, 2001

David, C. and Jeuffroy, M. H.: A sequential approach for improving AZODYN crop model under conventional and low-input conditions, Europ. J. Agronomy, 31, 177-182, 2009.

Downing, T. E., Harrison, P. A., Butterfield, R. E., and Lonsdale, K. G.: Climate change, climatic variability and agriculture in Europe: an integrated assessment, Environmental Change Unit, University of Oxford, Oxford, UK, 445 pp., 2000.

Fronzek, S., Carter T. R., Raisanen, J., Ruokolainen, L., and Luoto, M.: Applying probabilistic projections of climate change with impact models: a case study for sub-arctic palsa mires in Fennoscandia, Climatic Change, 99, 515-534, 2010.
García del Moral, L. F., Rharrabti, Y., Villegas, D., and Royo, C.: Evaluation of grain yield and its components in durum wheat under Mediterranean conditions: an onthogenic approach, Agron. J., 95, 266-274, 2003.

Gardner, M. W. and Dorling, S. R.: Artificial neural networks (the multilayer perceptron) - a review of applications in the atmospheric sciences, Atmos. Environ., 32, 2627-2636, 1998.

Giannakopoulos, C., Le Sager, P., Bindi, M., Moriondo, M., Kostopoulou, E., and Goodess, C. M.: Climatic changes and associated impacts in the Mediterranean resulting from a $2^{\circ} \mathrm{C}$ global warming, Global Planet. Change, 68, 209-224, 2009.

Gibelin, A. L. and Déqué, M.: Anthropogenic climate change over the Mediterranean region simulated by a global variable resolution model, Clim. Dyn., 20, 327-339, 2003.

Giorgi, F. and Lionello, P.: Climate change projections for the Mediterranean region, Global Planet. Change, 63, 90-104, 2008.

Harris, G. R., Collins, M., Sexton, D. M. H., Murphy, J. M., and Booth, B. B. B.: Probabilistic projections for 21st century European climate, Nat. Hazards Earth Syst. Sci., 10, 2009-2020, doi:10.5194/nhess-10-2009-2010, 2010.

Harrison, P. A., Butterfield, R. E., and Gawith, M. J.: Effects on winter wheat, sunflower and grassland in Europe, in: Climate change and agriculture in Europe: assessment of impacts and adaptations, edited by: Harrison, P. A., Butterfield, R. E., and Downing, T. E., Environmental Change Unit, University of Oxford, Oxford, UK, 330-385, 1995.

Haylock, M. R., Hofstra, N., Klein Tank, A. M. G., Klok, E. J., Jones, P. D., and New, M.: A European daily highresolution gridded data set of surface temperature and precipitation for 1950-2006, J. Geophys. Res., 113, D20119, doi:10.1029/2008JD010201, 2008.

Iglesias, A., Garrote, L., Quiroga, S., and Moneo, M.: Impacts of climate change in agriculture in Europe, PESETA-Agriculture study, Joint Research Centre, Luxembourg, EU, 2009.

Jamieson, P. D., Semenov, M. A., Brooking, I. R., and Francis, G. S.: Sirius: a mechanistic model of wheat response to environmental variation, Eur. J. Agron., 8, 161-179, 1998.

Jamieson, P. D., Bernsten, J., Ewert, F., Kimball, B. A., Olesen, J. E., Pinter Jr., P. J., Porter, J. R., and Semenov, M. A.: Modelling $\mathrm{CO}_{2}$ effects on wheat with varying nitrogen supplies, Agric. Ecosyst. Environ., 82, 27-37, 2000.

Jones, R. N.: Managing uncertainty in climate change projections - Issues for impact assessment, Climatic Change, 45, 403-419, 2000.

Kimball, B. A., Kobayashi, K., and Bindi, M.: Responses of agricultural crops to free-air $\mathrm{CO}_{2}$ enrichment, Adv. Agron., 77, 293 368, 2002.

McClelland, J. L. and Rumelhart, D. E. (Eds.): Parallel distributed processing: exploration in the microstructure of cognition, Vol. 1, MIT Press, Cambridge, MA, 1986.

Mearns, L. O., Hulme, M., Carter, T. R., Leemans, R., Lal, M., and Whetton, P.: Climate scenario development, in: Climate change 2001: impacts, adaptation, and vulnerability. Contribution of working group II to the third assessment report of the intergovernmental panel on climate change, edited by: McCarthy, J. J., Canziani, O. F., Leary, N. A., Dokken, D. J., and White, K. S., Cambridge University Press, Cambridge, UK, 739-768, 2001. 
Monitoring Agricultural Resources (MARS), European Commission Joint Research Centre URL http://mars.jrc.it/mars/ About-us/The-MARS-Unit, 2009.

Moriondo, M. and Bindi, M.: Comparison of temperatures simulated by GCMs, RCMs and statistical downscaling: potential application in studies of future crop development, Clim. Res., 30, 149-160, 2006.

Moriondo, M., Bindi, M., Kundzewicz, Z. W., Szwed, M., Chorynski, A., Matczak, P., Radziejewski, M., McEvoy, D., and Wreford, A.: Impact and adaptation opportunities for European agriculture in response to climatic change and variability, Mitig. Adapt. Strateg. Glob. Change, 7, 657-679, 2010.

Murphy, J. M., Booth, B. B. B., Collins, M., Harris, G. R., Sexton, D. M. H., and Webb, M. J.: A methodology for probabilistic predictions of regional climate change from perturbed physics ensembles, Phil. Trans. R. Soc. A, 365, 1993-2028, 2007.

Nakićenović, N. and Swart R. (Eds.): Special Report on Emissions Scenarios, Cambridge University Press, Cambridge, UK, 599 pp., 2000.

New, M., Lopez, A., Dessai, S., and Wilby, R.: Challenges in using probabilistic climate change information for impact assessments: an example from the water sector, Phil. Trans. R. Soc. A, 365, 2117-2131, 2007.

Olesen, J. E. and Bindi, M.: Consequences of climate change for European agricultural productivity, land use and policy, Europ. J. Agronomy, 16, 239-262, 2002.

Olesen, J. E., Carter, T. R., Díaz-Ambrona, C. H., Fronzek, S., Heidmann, T., Hickler, T., Holt, T., Minguez, M. I., Morales, P., Palutikof, J. P., Quemada, M., Ruiz-Ramos, M., Rubæk, G. H., Sau, F., Smith, B., and Sykes, M. T.: Uncertainties in projected impacts of climate change on European agriculture and terrestrial ecosystems based on scenarios from regional climate models, Climatic Change, 81, 123-143, 2007.

Parry, M. L., Rosenzweig, C., Iglesias, A., Livermore, M., and Fischer, G.: Effects of climate change on global food production under SRES emissions and socio-economic scenarios, Global Environ. Change, 14, 53-67, 2004.

Porter, J. R. and Semenov, M. A.: Crop responses to climatic variation, Phil. Trans. R. Soc. B, 360, 2021-2035, 2005.
Reidsma, P., Ewert, F., Boogaard, H., and van Diepen, K.: Regional crop modelling in Europe: The impact of climatic conditions and farm characteristics on maize yields, Agri. Syst., 100, 51-60, 2009.

Rumelhart, D. E., Hinton, G. E., and Williams, R. J.: Learning internal representations by error propagation, in: Parallel distributed processing: explorations in the microstructure of cognition, $\mathrm{Vol}$ 1, McClelland, J. L. and Rumelhart, D. E., MIT Press, Cambridge, MA, 318-362, 1986.

Schneider, S.: What is 'dangerous' climate change?, Nature, 411, 17-19, 2001.

Tebaldi, C. and Knutti, R.: The use of the multi-model ensemble in probabilistic climate projections, Phil. Trans. R. Soc. A, 365, 2053-2075, 2007.

Tebaldi, C. and Lobell, D. B.: Towards probabilistic projections of climate change impacts on global crop yields, Geophys. Res. Lett., 35, L08705, doi:10.1029/2008GL033423, 2008.

Trigo, R. M. and Palutikof, J. P.: Simulation of daily temperatures for climate change scenarios over Portugal: a neural network model approach, Clim. Res., 13, 45-59, 1999.

Triossi, A.: Studio della dinamica dell'accumulo proteico nella granella di frumento duro ai fini di una caratterizzazione agroclimatica delle potenzialita' produttive (qualitative e quantitative), Ph.D. thesis, Department of Agronomy and Land Management, University of Florence, Italy, 148 pp., 2006.

Tubiello, F. N., Donatelli, M., Rosenzweig, C., and Stockle, C. O.: Effects of climate change and elevated $\mathrm{CO}_{2}$ on cropping systems: model predictions at two Italian locations, Europ. J. Agronomy, 13, 179-189, 2000.

Widrow, B., Rumelhart, D. E., and Lehr, M. A.: Neural networks: Applications in industry, business and science, Communications of the ACM, 37, 93-105, 1994.

Zhang, H. and Oweis, T.: Water-yield relations and optimal irrigation scheduling of wheat in the Mediterranean region, Agr. Water Manage., 38, 195-211, 1999.

Zhang, G., Eddy Patuwo, B., and Hu, Y. M.: Forecasting with artificial neural networks: The state of the art, Internat. J. Forecast., 14, 35-62, 1998. 